Article

\title{
Hexane-isopropanol Extraction and Quality Assessment of Omega-3 Fish Oil from Atlantic Salmon (Salmo Salar)
}

\author{
Iberahim NI ${ }^{1,}$, Tan BC ${ }^{2}$ and Sohaimi KSA ${ }^{3}$, \\ 1 Faculty of Chemical Engineering Technology, Universiti Malaysia Perlis, Sungai Chuchuh, 02100, Padang \\ Besar, Perlis, Malaysia; izzatiiberahim@unimap.edu.my \\ 2 Faculty of Chemical Engineering Technology, Universiti Malaysia Perlis, Sungai Chuchuh, 02100, Padang \\ Besar, Perlis, Malaysia; bengchoo96@hotmail.com \\ 3 Faculty of Chemical Engineering Technology, Universiti Malaysia Perlis, Sungai Chuchuh, 02100, Padang \\ Besar, Perlis, Malaysia; syairah@unimap.edu.my \\ * Correspondence izzatiiberahim@unimap.edu.my; Tel.: (+06-17-6692384)
}

\begin{abstract}
Atlantic salmon (Salmo Salar) is one of the fish species that rich in omega-3 fatty acids. Consumption of omega-3 fatty acids can lower down the risk of cardiovascular disease and coronary heart disease. The extraction of omega-3 fish oil from Atlantic salmon by using hexane and isopropanol was conducted in this research. Response Surface Methodology (RSM) was used to study the impact of parameters which were temperature $\left(50-90^{\circ} \mathrm{C}\right)$, centrifuge speed (1000-3000 rpm) and solvent ratio of hexane to isopropanol (0.5-1.5) to the percentage of oil yield. The results obtained shows that $15.23 \% \pm 0.61$ of oil yield from Atlantic salmon under an optimum condition of $70^{\circ} \mathrm{C}, 3000 \mathrm{rpm}$ and solvent ratio of hexane to isopropanol of 1.5. The acid value, peroxide value and p-anisidine value of the fish oil obtained were $7.48 \mathrm{mg} \mathrm{KOH} / \mathrm{g}, 1.94 \mathrm{meq} / \mathrm{kg}$ and 5.56 respectively which were all within the acceptable limit which stipulated by Global Organization for EPA and DHA (GOED) and Food and Agricultural Organization of the United Nations (FAO). The FTIR analysis proved the presence of alkane and carboxylic acid in the fish oil. Furthermore, GC-MS analysis showed that the fish oil contains higher monounsaturated fatty acids (MUFA) contents followed by polyunsaturated fatty acids (PUFA) and $4.5525 \%$ of total omega-3 fatty acids.
\end{abstract}

Keywords: hexane-isopropanol extraction; omega-3 fish oil; Atlantic salmon

\section{Introduction}

Atlantic salmon (Salmo Salar) is one of the species that rich in lipids, omega-3 fatty acids, and excellent grade of protein. Atlantic salmon has many advantages to human such as antiinflammation, anti-cancer, anti-diabetic and antioxidant. Hence, it is suitable to be utilized for beneficial fish oil production [1].

Fish oil is a great nutritional product due to the presence of long chain omega-3 polyunsaturated fatty acids (PUFA), such as docosahexaenoic acid (DHA) and eicosapentaenoic acid (EPA). DHA and EPA having beneficial effects in cardiovascular diseases, lowering blood cholesterol and reduce risk of several diseases [2]. EPA can assist the blood cells formation, stimulate blood circulation by stabilize the circulatory system. It is essential for the brain's nerve cells development [3]. DHA plays a key role in the function of vertebrate retina and nervous tissues [4].

One of the method of fish oil extraction is solvent extraction whereby soluble solids or liquid constituent present is removed from solids or liquid by the use of organic solvent [5]. Organic solvent will disturb the interaction forces between lipids and tissue matrix and hence extract the oil. Oils are highly soluble in the organic solvent such as hexane, chloroform, cyclohexane, and methanol [6]. The organic solvent that used in this study was hexane and isopropanol.

There were several parameters that will affect the efficiency of the extraction of fish oil which including temperature, centrifuge speed and solvent ratio. The research had focused on the optimization of the solvent extraction of oil process to improve the percentage of oil yield. The 
optimization was carried out by using response surface methodology (RSM) of central composite design $(\mathrm{CCD})$. The parameters that studied in this research were temperature $\left(50^{\circ} \mathrm{C}, 70^{\circ} \mathrm{C}, 90^{\circ} \mathrm{C}\right)$, centrifuge speed (1000rpm, $2000 \mathrm{rpm}, 3000 \mathrm{rpm})$, and solvent ratio of hexane to isopropanol $(0.5,1.0$, $1.5)$.

\section{Materials and Methods}

\subsection{Raw materials}

Raw salmon was bought from the hypermarket Giant which is located at Kangar, Perlis. The salmon was stored in the freezer at $-19^{\circ} \mathrm{C}$ for further use.

\subsection{Optimization for fish oil yield}

Design of Expert 11 (DOE) was used for optimization. Response Surface Methodology (RSM) was used to investigate the relationship between response and process parameters. In this research, Central Composite designs (CCD) was used to determine the number of run that require in order to determine the maximum percentage of oil recovery. For three factors at three level of runs, CCD has 20 experiments with 6 experiment are runs at central point (refer to table 2). Table 1 shows the range of each parameter studied in optimization.

Table 1 Range of parameter for optimize the recovery of fish oil

\begin{tabular}{cccc}
\hline Parameter & Unit & Minimum & Maximum \\
\hline Solvent ratio & - & 0.5 & 1.5 \\
Heating temperature & ${ }^{\circ} \mathrm{C}$ & 50 & 90 \\
Centrifuge speed & $\mathrm{rpm}$ & 1000 & 3000 \\
\hline
\end{tabular}

\subsection{Extraction of fish oil}

Approximately $20 \mathrm{~g}$ of salmon was homogenized for $30 \mathrm{~s}$ with $120 \mathrm{~mL}$ of hexane and $240 \mathrm{~mL}$ isopropanol which is in a volume ratio of 1:2. The mixture was then transferred to the water bath which heated at $50^{\circ} \mathrm{C}$ in for $15 \mathrm{~min}$. It was then centrifuged for $10 \mathrm{~min}$ at $500 \mathrm{rpm}$. After centrifugation, the mixture was filtered by using filter paper. The solids that was separated out are sent to centrifugation again which operated at the same speed and time. $40 \mathrm{~mL}$ mixture of hexane and isopropanol were added into the precipitate prior the centrifugation. The solids was discarded and the filtrate was then passed through $150 \mathrm{ml}$ of aqueous sodium sulfate. After $10 \mathrm{~min}$, the sodium sulfate was removed and discarded by filtration. The organic layer within the filtrate was separated in the separatory funnel and evaporated with a rotary evaporator. The remaining mixture which was obtained was the fish oil [7]. The experiment was repeated by using different solvent ratio of hexane to isopropanol which is $180 \mathrm{~mL}: 180 \mathrm{~mL}$ (1:1) and $216 \mathrm{~mL}: 144 \mathrm{~mL}$ (3:2). Different heating temperature was also used to heat the sample which was $70^{\circ} \mathrm{C}$ and $90^{\circ} \mathrm{C}$ and the centrifuge speed that used are 2000rpm and 3000rpm. The experiment was carried out with respect to the value of heating temperature, centrifuge speed and solvent ratio according to table 2 .

\subsection{Fourier Transform Infrared Spectroscopic (FTIR) analysis}

The components present in the fish oil was characterized by using the FTIR portable spectrometer (PerkinElmer) which is equipped with a temperature controlled, 5-bounce ZnSe crystal ATR. The sample was sealed with a parafilm and allowed to cool to room temperature before collection of data. Then, $80 \mu \mathrm{L}$ of sample was deposited on the ATR sensor using a micropipette. The temperature was kept at $65^{\circ} \mathrm{C}$. The spectra was performed at $4 \mathrm{~cm}-1$ resolution for $4000-700 \mathrm{~cm}-1$. The spectra was gained in terms of absorbance using PerkinElmer Spectrum Version 10.5.2. 


\subsection{Preparation of Fatty Acid Methyl Esters (FAME)}

FAME was prepared by base or acid catalysed esterification. $0.1 \mathrm{~g}$ of lipids extract was weighed by weighing balance. It was then transferred into a centrifuge tube. After that, $1.5 \mathrm{~mL}$ of methylene chloride, $0.01 \%$ BHT and $3.0 \mathrm{~mL}$ of Hilditch reagent were added. The Hilditch reagent was prepared by adding $1.5 \mathrm{~mL}$ of concentrated $\mathrm{H} 2 \mathrm{SO} 4$ to $100 \mathrm{~mL}$ of dry methanol. The sample was capped and vortexed for about 5 seconds. It was then undergoes sonication for 4 minutes. Next, the tube was flushed with nitrogen, capped and sealed with Teflon tape and heated for 1 hour at $100^{\circ} \mathrm{C}$ in an oven. The tube was allowed to cool to room temperature. $0.5 \mathrm{~mL}$ of saturated sodium bicarbonate solution was added slowly to the tube, followed by $1.5 \mathrm{~mL}$ of hexane. The tube was then vortexed for $5-10$ seconds. The top organic layer was transferred to a new tube and hexane was evaporated with a gentle stream of nitrogen. $0.5 \mathrm{~mL}$ of hexane was added to the fatty acids for re-suspension, capped with nitrogen and Teflon tape. It was then sonicated for an additional of 4 minutes [8]. The sample produced will undergoes GC-MS analysis.

\subsection{Determination of acid value}

$2 \mathrm{~mL}$ of $1 \%$ phenolphthalein indicator and $125 \mathrm{~mL}$ of 1:1 toluene-isopropyl alcohol was added into a $250 \mathrm{~mL}$ of glass Erlenmeyer flask. The sample was neutralised by $0.1 \mathrm{~N} \mathrm{KOH}$ until a faint but permanent pink colour appears. $0.5-0.25 \mathrm{~g}$ of oil sample and $125 \mathrm{~mL}$ of neutralised solvent mixture was added and mixed in another $250 \mathrm{~mL}$ of Erlenmeyer flask. The sample was then titrated with $0.1 \mathrm{~N}$ $\mathrm{KOH}$ until permanent pink colour appear. The acid value of oil with unit of $\mathrm{mg} \mathrm{KOH} / \mathrm{g}$ of sample will be determined by (1):

$$
\text { Acid value }=((\mathrm{A}-\mathrm{B}) \times \mathrm{N} \times 56.1) / \mathrm{W}
$$

Where: $\mathrm{A}=$ Volume of standard alkali used in the titrating sample $(\mathrm{mL})$

$$
\begin{aligned}
& \mathrm{B}=\text { Volume of standard alkali used in the titrating the blank }(\mathrm{mL}) \\
& \mathrm{N}=\text { Normality of standard alkali } \\
& \mathrm{W}=\text { Mass of sample }(\mathrm{g}) \\
& 56.1=\text { molecular weight of } \mathrm{KOH} \text { in grams }
\end{aligned}
$$

\subsection{Determination of peroxide value (PV)}

The oil sample was filtered by using Whatman No.40 filter paper in order to remove the moisture and impurities. $2.5 \mathrm{~g}$ of filtered oil sample was weighted and added into $250 \mathrm{~mL}$ Erlenmeyer flask. $50 \mathrm{~mL}$ of $3: 2$ acetic acid-chloroform was added and swirled for well mixing. $1 \mathrm{~mL}$ of saturated potassium iodide (KI) solution was added into the sample and allowed to stand for exactly of $1 \mathrm{~min}$. Next, $100 \mathrm{~mL}$ of distilled water was added immediately after standing time and swirled for mixing. The sample was then titrated with $0.1 \mathrm{~N}$ sodium thio-sulfate until the light yellow colour appeared. $1 \mathrm{~mL}$ of starch indicator solution was added for titration with agitation until the solution turn colourless. On the other hand, a blank sample was prepared without the addition of oil sample. The peroxide value (miliequivalents peroxide/1000g sample) was determined by the equation below:

$$
\text { Peroxide value }=((\mathrm{S}-\mathrm{B}) \times \mathrm{N} \times 1000) / \mathrm{W}
$$

Where: $\mathrm{B}=$ Volume of standard potassium thiosulfate used for titration of blank $(\mathrm{mL})$

$\mathrm{S}=$ Volume of standard potassium thiosulfate used for titration of sample $(\mathrm{mL})$ 


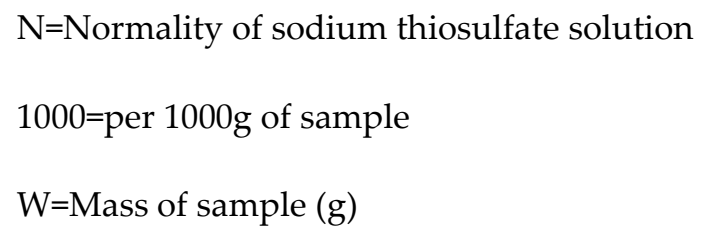

\subsection{Determination of $p$-anisidine value}

The oil sample was filtered using Whatman No. 40 filter paper. A $0.5-4 \pm 0.001 \mathrm{~g}$ of oil sample was added into a $25 \mathrm{~mL}$ volumetric flask. $25 \mathrm{~mL}$ of iso-octane was added into the sample, the sample was then dissolved and diluted. Spectrophotometer was used to measure the absorbance $(A B)$ at $350 \mathrm{~nm}$. A $5 \mathrm{ml}$ of the oil sample was pipetted into a test tube and $1 \mathrm{~mL}$ of p-anisidine reagent was also added. $5 \mathrm{~mL}$ of iso-octane and $1 \mathrm{~mL}$ of $\mathrm{p}$-anisidine reagent was added into another test tube as a blank. The $\mathrm{p}$-anisidine was prepared by using $0.25 \mathrm{~g}$ of $\mathrm{p}$-anisinide with $100 \mathrm{~mL}$ of glacial acetic acid. After 10 minutes, the absorbance (AS) oil sample was measured using spectrophotometer. The p-anisidine value was calculated by using equation below:

$$
\mathrm{p} \text {-anisidine value }=\left(25\left(1.2 \mathrm{~A} \_\mathrm{s} \quad \text { \-A】_B }\right)\right) / \mathrm{W}
$$

Where: AS = Absorbance of the fat solution after reaction with the p-anisidien reagent

$\mathrm{AB}=$ Absorbance of the fat solution

$\mathrm{W}=$ Weight of the oil $(\mathrm{g})$

\section{Results}

\subsection{Optimization solvent extraction of fish oil with response surface methodology}

The experimental condition according to RSM design and percentage of fish oil yield obtained from the experiment were presented in table 2 . The data of the percentage of oil yield obtained was used for statistical analysis in order to optimize the parameters which were temperature, centrifuge speed and solvent ratio. The percentage of oil yield obtained were ranged from 3\% to $15.18 \%$ with a mean value of $11.51 \%$. By using the empirical data, a model equation to predict the effects of temperature, centrifuge speed and solvent ratio on the oil yield was developed. The model equation for the fish oil extraction which expressed the effect of parameters in terms of linear, quadratic, and cross-product term is as follows:

Percentage of oil yield $=8.98545+0.114718 \mathrm{~A}-0.004324 \mathrm{~B}+5.77052 \mathrm{C}+0.000042 \mathrm{AB}+$
$0.160625 \mathrm{AC}-0.000192 \mathrm{BC}-0.003077 \mathrm{~A}^{2}+5.39091 \mathrm{E}-07 \mathrm{~B}^{2}-5.36364 \mathrm{C}^{2}$

Where $\mathrm{A}=$ temperature $\left({ }^{\circ} \mathrm{C}\right), \mathrm{B}=$ centrifuge speed $(\mathrm{rpm})$ and $\mathrm{C}=$ solvent ratio. The optimum conditions were obtained at $70^{\circ} \mathrm{C}, 3000 \mathrm{rpm}$ and 1.5 solvent ratio. The predicted oil yield obtained by using Equation (4) is $15.23 \%$ and was experimentally verified at $15.23 \% \pm 0.61$.

Table 2 Central Composite Design matrix of factors and the response of oil yield for Atlantic salmon.

\begin{tabular}{llllll}
$\begin{array}{l}\text { Std } \\
\text { run }\end{array}$ & Run & Factor 1 & Factor 2 & Factor 3 & Response \\
\hline
\end{tabular}




\begin{tabular}{cccccc}
\hline & & $\begin{array}{c}\text { A: } \\
\text { Temperature } \\
\left({ }^{\circ} \text { C) }\right.\end{array}$ & $\begin{array}{c}\text { B: Centrifuge } \\
\text { speed (rpm) }\end{array}$ & $\begin{array}{c}\text { C: } \\
\text { Solvent ratio }\end{array}$ & $\begin{array}{c}\text { Percentage of oil } \\
\text { yield (\%) }\end{array}$ \\
\hline 19 & 1 & 70 & 2000 & 1 & 12.41 \\
13 & 2 & 70 & 2000 & 0.5 & 8.1 \\
11 & 3 & 70 & 1000 & 1 & 12.49 \\
3 & 4 & 50 & 3000 & 0.5 & 10.84 \\
17 & 5 & 70 & 2000 & 1 & 12.39 \\
1 & 6 & 50 & 1000 & 0.5 & 10.69 \\
2 & 7 & 90 & 1000 & 0.5 & 3 \\
20 & 8 & 70 & 2000 & 1 & 13.3 \\
12 & 9 & 70 & 3000 & 1 & 12.87 \\
16 & 10 & 70 & 2000 & 1 & 12.24 \\
6 & 11 & 90 & 1000 & 1.5 & 12.09 \\
14 & 12 & 70 & 2000 & 1.5 & 13.5 \\
7 & 13 & 50 & 3000 & 1.5 & 13.12 \\
5 & 14 & 50 & 1000 & 1.5 & 14.04 \\
4 & 15 & 90 & 3000 & 0.5 & 5.79 \\
15 & 16 & 70 & 2000 & 1 & 12.85 \\
18 & 17 & 70 & 2000 & 1 & 13.54 \\
10 & 18 & 90 & 2000 & 1 & 9.99 \\
8 & 19 & 90 & 3000 & 1.5 & 15.18 \\
9 & 20 & 50 & 2000 & 1 & 11.83 \\
\hline
\end{tabular}

The results of Analysis of Variance (ANOVA) for RSM are shown in table 3. The high coefficient of determination values $\left(\mathrm{R}^{2}\right)$ which was 0.9738 established that a close agreement between the experimental data and the predicted values calculated using the models had been attained. This indicates that $97.38 \%$ of the variations could be demonstrated by the fitted model, indicating a consequent fit of the model to the experimental data. It was suggested that the value of $\mathrm{R}^{2}$ should be at least 0.80 for a good fit of a mode [9]. A closer experimental and predicted results implied a better acceptability of the regression equation [10]. The difference between the value of Adjusted $\mathrm{R}^{2}$ of 0.9502 and Predicted $R^{2}$ of 0.8621 strengthen the accuracy of prediction and general availability of the model as this difference should not be greater than 0.2 [11].

Table 3 Fit Statistics

\begin{tabular}{clll}
\hline Mean & 11.51 & $\mathbf{R}^{2}$ & 0.9738 \\
C.V. \% & 5.65 & Adjusted R & 0.9502 \\
Adeq & 25.8368 & Predicted $\mathbf{R}^{2}$ & 0.8621 \\
Precision & & & \\
\hline
\end{tabular}

The lack of fit that used to measure the fitness of the model was found to be not significant $(p>0.05)$ (refer to table 4). This implicates that the number of experiments were satisfactorily for the determination of the consequence of independent variables on the percentage of oil yield. The 
probability ( $p$-value) of the model significance was less than 0.0001 which suggest that the model was significant and applicable for this experiment. The Coefficient of Variation (CV) measure the reproducibility of the model. In general, the model that having CV that is less than $10 \%$ can be accounted reasonably reproducible [10]. In this case, the CV obtained was $5.65 \%$ which was acceptable. Hence, the developed model can sufficiently represent the real relationship between the parameters chosen.

A statistical analysis of the response from ANOVA (refer to table 4) computed that the parameter that with the largest effect on the oil yield was linear term of heating temperature $(p<0.0001)$ and solvent ratio $(p<0.0001)$, followed by interaction of heating temperature with solvent ratio $(p<0.0001)$, , interaction of heating temperature with centrifuge speed $(\mathrm{p}<0.05)$, square value of solvent ratio $(p<0.05)$, square value of temperature $(p<0.05)$, , centrifuge speed $(p<0.05)$ were significantly affect the percentage of oil yield.

Table 4 Analysis of Variance (ANOVA) for percentage of oil yield.

\begin{tabular}{|c|c|c|c|c|c|c|}
\hline Source & $\begin{array}{l}\text { Sum of } \\
\text { Squares }\end{array}$ & $\mathrm{df}$ & $\begin{array}{l}\text { Mean } \\
\text { Square }\end{array}$ & $\begin{array}{r}\text { F- } \\
\text { value }\end{array}$ & $\begin{array}{r}\text { p- } \\
\text { value }\end{array}$ & Remarks \\
\hline \multirow[t]{2}{*}{ Model } & 156.88 & 9 & 17.43 & 41.26 & $<$ & Significant \\
\hline & & & & & 0.0001 & \\
\hline A- & 20.94 & 1 & 20.94 & 49.56 & $<$ & Significant \\
\hline Temperature & & & & & 0.0001 & \\
\hline B-Centrifuge & 3.01 & 1 & 3.01 & 7.13 & 0.0235 & Significant \\
\hline C-Solvent & 87.08 & 1 & 87.08 & 206.12 & $<$ & Significant \\
\hline ratio & & & & & 0.0001 & \\
\hline $\mathbf{A B}$ & 5.53 & 1 & 5.53 & 13.08 & 0.0047 & Significant \\
\hline AC & 20.64 & 1 & 20.64 & 48.85 & $<$ & Significant \\
\hline & & & & & 0.0001 & \\
\hline BC & 0.0741 & 1 & 0.0741 & 0.1754 & 0.6842 & $\begin{array}{c}\text { Not } \\
\text { significant }\end{array}$ \\
\hline $\mathbf{A}^{2}$ & 4.17 & 1 & 4.17 & 9.86 & 0.0105 & Significant \\
\hline $\mathbf{B}^{2}$ & 0.7992 & 1 & 0.7992 & 1.89 & 0.1990 & $\begin{array}{c}\text { Not } \\
\text { significant }\end{array}$ \\
\hline $\mathrm{C}^{2}$ & 4.94 & 1 & 4.94 & 11.70 & 0.0065 & Significant \\
\hline Residual & 4.22 & 10 & 0.4225 & & & \\
\hline Lack of fit & 2.79 & 5 & 0.5584 & 1.95 & 0.2409 & $\begin{array}{c}\text { Not } \\
\text { significant }\end{array}$ \\
\hline Pure error & 1.43 & 5 & 0.2866 & & & \\
\hline Cor Total & 161.11 & 19 & & & & \\
\hline
\end{tabular}

It can clearly observed that from figure 1 and figure 2, the oil yield was increased slowly from $50^{\circ} \mathrm{C}$ and reach maximum at $70^{\circ} \mathrm{C}$, and start to reduce when the temperature was rose to around $75^{\circ} \mathrm{C}$ and above. The effect of temperature on the oil yield is closely related to the volatility of the mixture of oil and solvent. At low temperature, the volatility of the mixture is low, and hence it reduce the ability of the solvent to dissolve in the oil. On the other hand, the increasing of temperature results 
in the increment of volatility of the solvent and thus, dissolving power of solvent in the oil increased [12]. The increasing of solvent dissolving power will increase the penetration and diffusion of solvent molecules into the matrix of solids and hence the oil extracted by solvent increased [13]. However, the reduction of oil yield at high temperature was due to the decreasing of the solvent density, which causes the ability of the solvent to dissolve in oil become lower [12].

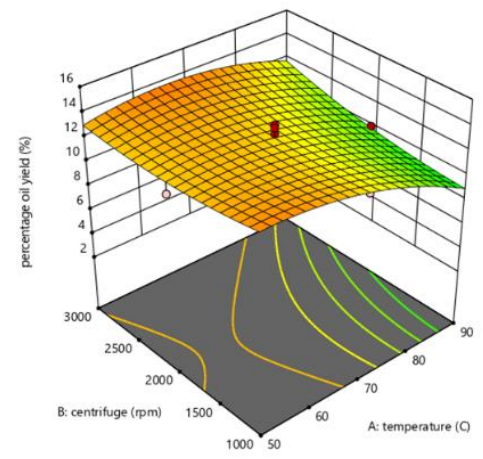

Figure 1 Response surface for oil yield as a function of temperature and centrifuge at a fixed solvent ratio of 1.0.

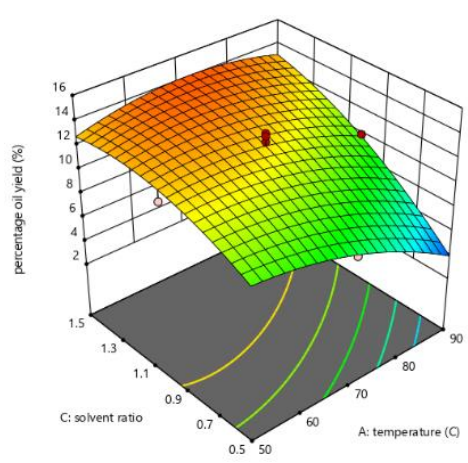

Figure 2 Response surface for oil yield as a function of temperature and solvent ratio at a fixed centrifuge speed at 2000rpm.

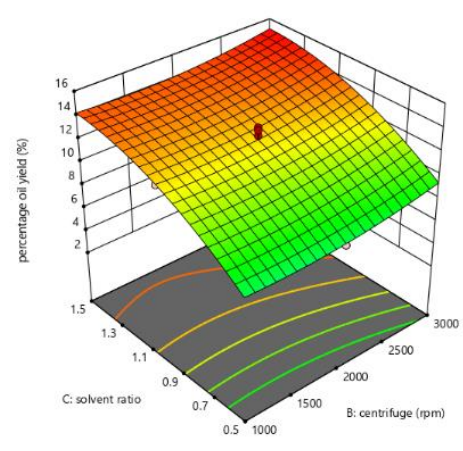

Figure 3 Response surface for oil yield as a function of centrifuge and solvent ratio at a fixed temperature at $70^{\circ} \mathrm{C}$.

The impact of centrifuge speed to the percentage of oil yield can referred to figure 1 and figure 3 . It was clearly showed that the oil yield increased when the centrifuge speed increased. The oil yield was maximum when the centrifuge speed at $3000 \mathrm{rpm}$. When the centrifuge speed increased, the centrifugal force that used to separate the oil from the solid mixture increased, and hence facilitate the separation of oil from the solid cake and increasing the oil extracted. A similar result was obtained by [14] where the oil yield was increased significantly when the speed of centrifugation is higher.

From figure 2 and figure 3, it was clearly showed that the optimum solvent ratio of hexane to isopropanol obtained was 1.5 (3:2). Isopropanol was act as a co-extractant of oil. Since the cell membrane is mostly made up with protein molecules which encloses the polar lipids such as phospholipids, glycolipids and cholesterol, hence the isopropanol which acts as a polar solvent was used to destroy the complex lipid-protein interactions before the lipids being extracted out by hexane [15]. At solvent ratio of 0.5 , too much of isopropanol present causing the solution become too polar and lower down the efficiency of oil extraction. Hence, solvent ratio of 3:2 is most suitable for hexane to isopropanol to maintain the non-polar characteristics for oil extraction and polar characteristics for the disruption of protein matrix. 


\subsection{Fourier-transform Infrared Spectroscopy (FTIR) analysis}

The FTIR spectra of the fish oil samples have distinct bands that can be used to indicate several functional groups found in lipids. Figure 4 shows the spectrum of the oil sample with the peak positions of important functional group frequencies labelled. The C-H stretching at $3008.58 \mathrm{~cm}^{-}$ 1, C-H sp3 stretching at $2922.57 \mathrm{~cm}^{-1}$ and $2853.68 \mathrm{~cm}^{-1}$ indicate the present of alkane in the fish oil sample. The present of $1459.67 \mathrm{~cm}^{-1}$ (C-H bending) indicate the present of aliphatic methyl functional group in the oil. The $719.52 \mathrm{~cm}^{-1}$ peaks was due to the bending (rocking) motion associated with four or more $\mathrm{CH}_{2}$ groups in an open chain which determine the present of alkane in the oil. Besides that, the peak of $1748.00 \mathrm{~cm}^{-1}(\mathrm{C}=\mathrm{O})$ stretching and $1157.20 \mathrm{~cm}^{-1}(\mathrm{C}-\mathrm{O}$ stretching) indicate the present of the carboxylic acid [16]. Hence, the fatty acid chain will contain methyl group and double bond between the carbon atoms causing the present of unsaturated fatty acid in the oil [17].

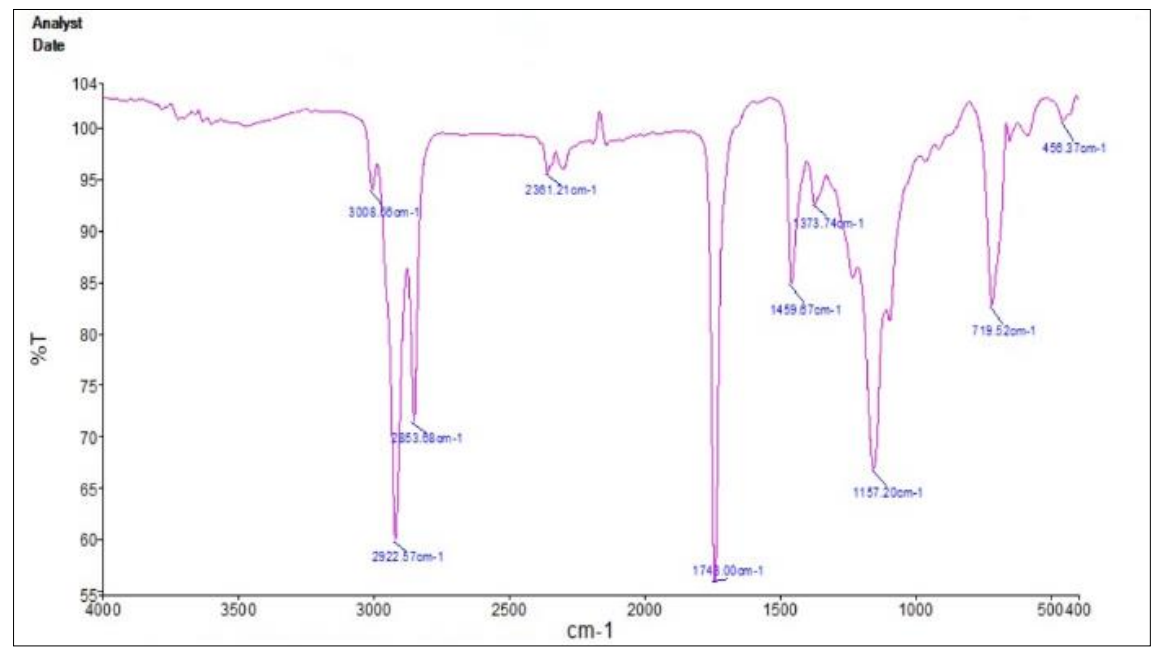

Figure 4 FTIR spectra of salmon oil extracted.

\subsection{Fatty acid methyl esters (FAME) analysis}

The major fatty acid content in the samples was monounsaturated fatty acids (MUFA) followed by polyunsaturated fatty acids (PUFA) (refer to table 5). The dominant saturated and monounsaturated fatty acids present in the oil was palmitic acid (6.8449\%) and oleic acid (38.0623\%) respectively. On the other hand, the major polyunsaturated fatty acids contained in the fish oil were linoleic acid (11.0473\%), docosahexaenoic acid (DHA) (2.0946\%) and eicosapentaenoic acid (EPA) $(1.5124 \%)$. The similar results was obtained by [8]. The omega-3 fatty acids present were eicosapentaenoic acid (EPA), heneicosapentaenoic acid (HPA), docosapentaenoic acid (DPA) and docosahexaenoic acid (DHA). Omega-6 fatty acids such as linoleic acid, gamma-linolenic acid, eicosadienoic acid were also found in the fish oil. The total omega-3 and omega- 6 fatty acids liberated in the fish oil were $4.5525 \%$ and $13.238 \%$ respectively. One of the factor that may causing the oil with low omega-3 fatty acids was due to oxidation. The presence of high quantities of PUFA makes the oxidation process become more favourable, which leads to the subsequent deterioration of the oil [17]. 
Table 5 Fatty acid composition of fish oil extracted.

\begin{tabular}{|c|c|c|c|}
\hline Fatty acids & Isomer & Common name & $\begin{array}{c}\% \\
\text { composition }\end{array}$ \\
\hline \multirow{11}{*}{$\begin{array}{l}\text { Saturated fats } \\
\text { (SFA) }\end{array}$} & C9:0 & Nonanoic acid & 0.0211 \\
\hline & C14:0 & Myristic acid & 1.1319 \\
\hline & C15:0 & Pentadecanoic acid & 0.082 \\
\hline & C16:0 & Palmitic acid & 6.8449 \\
\hline & C17:0 & Heptadecanoic acid & 0.1677 \\
\hline & C18:0 & Stearic acid & 1.9452 \\
\hline & C20:0 & Arachidic acid & 0.1793 \\
\hline & \multicolumn{2}{|c|}{ Total SFA } & 10.3721 \\
\hline & C16:1 n-7 & Palmitoleic acid & 2.6349 \\
\hline & C16:1 n-9 & Cis-7 Hexadecenoic acid & 0.0587 \\
\hline & C17:1(c10) & Heptadecenoic acid & 0.0925 \\
\hline \multirow{11}{*}{$\begin{array}{l}\text { Monounsaturated } \\
\text { fats (MUFA) }\end{array}$} & C18:1 n-5 & Octadecenoic acid & 0.4028 \\
\hline & C18:1 n-7 & Vaccenic acid & 0.4028 \\
\hline & C18:1 n-9 & Oleic Acid & 38.0623 \\
\hline & C20:1 n-9 & Gondoic acid & 1.1557 \\
\hline & C22:1 n-9 & Erucic acid & 0.3808 \\
\hline & \multicolumn{2}{|c|}{ Total MUFA } & 43.1905 \\
\hline & C18:2 n-6 & Linoleic acid & 11.0473 \\
\hline & C18:3 n-4 & Linolenic acid & 0.2117 \\
\hline & C18:3 n-6 & Gamma-linolenic acid & 0.1624 \\
\hline & C20:2 n-6 & Eicosadienoic acid & 0.3267 \\
\hline & C20:3 n-6 & $\begin{array}{l}\text { Dihomo-gamma-linolenic } \\
\text { acid }\end{array}$ & 0.2507 \\
\hline Polyunsaturated & C20:4 n-6 & Arachidonic acid & 1.2392 \\
\hline \multirow[t]{9}{*}{ Fats (PUFA) } & $C 20: 5 n-3$ & Eicosapentaenoic acid (EPA) & 1.5124 \\
\hline & $C 21: 5 n-3$ & $\begin{array}{l}\text { Heneicosapentaenoic } \\
\text { acid (HPA) }\end{array}$ & 0.0892 \\
\hline & $C 22: 5 n-3$ & $\begin{array}{l}\text { Docosapentaenoic acid } \\
\text { (DPA) }\end{array}$ & 0.8563 \\
\hline & $C 22: 6 n-3$ & (DHA) & 2.0946 \\
\hline & \multicolumn{2}{|c|}{ Other PUFA } & 0.1849 \\
\hline & \multicolumn{2}{|c|}{ Total Omega 3 fatty acids } & 4.5525 \\
\hline & \multicolumn{2}{|c|}{ Total Omega 6 fatty acids } & 13.238 \\
\hline & \multicolumn{2}{|c|}{ Total PUFA } & 17.9754 \\
\hline & \multicolumn{2}{|c|}{ Other compound } & 28.782 \\
\hline
\end{tabular}




\subsection{Acid value}

The acid value was used to establish the content of free fatty acid in oil. The acid value indicates the amount of $\mathrm{KOH}(\mathrm{mg})$ needed in order to neutralize one gram of oil. The acceptable limit of acid value of acid value is $7-8 \mathrm{mg} / \mathrm{KOH} \mathrm{g}[8]$. In the present study, the acid value of the fish oil extracted was found to be $7.48 \mathrm{mg} \mathrm{KOH} / \mathrm{g}$ which was within the acceptable limit. Factors such as oil composition, extraction method, and freshness of the raw material will highly affect the acid value of the oil [8].

\subsection{Peroxide value}

The peroxide value indicates the amount of hydroperoxides in the oil. Peroxide value was used to measure the rancidity of oil. The lower the peroxide value, the lower the ability of oil become rancid [18]. For a quality fish oil, the peroxide value of fish oil must $\leq 5 \mathrm{meq} / \mathrm{kg}$ which was stipulated by Global Organization for EPA and DHA (GOED) and Food and Agricultural Organization of the United Nations (FAO). In this research, the peroxide value of the fish oil obtained was $1.94 \mathrm{meq} / \mathrm{kg}$ which was within the acceptable range. Heat, light and oxygen are important factor that causing the acceleration of the oil become rancid [19].

\subsection{P-anisidine value}

P-anisidine value is used to indicate the secondary oxidation products which cause by the decomposition of the very unstable hydroperoxides [8]. It measure the oxidative status and flavour quality of the oil [1]. The p-anisidine of the fish oil extracted was 5.56 which were within the acceptable limit. According to Global Organization for EPA and DHA (GOED) and Food and Agricultural Organization of the United States (FAO), the p-anisidine value of oil must $\leq 20$ for a quality and human edible fish oil [1].

\section{Conclusion}

Fish oil had been successfully extracted by using solvent extraction method with hexane and isopropanol. The parameters which were temperature, centrifuge speed and solvent ratio were used to determine the percentage of oil yield. The optimum value of oil yield was $15.23 \% \pm 0.61$ at $70^{\circ} \mathrm{C}$, centrifuge speed of $3000 \mathrm{rpm}$ and solvent ratio of 1.5. In FTIR analysis, the functional group such as alkane and carboxylic acids were present in the fish oil. Moreover, the acid value, peroxide value and p-anisidine value of fish oil extracted were $7.48 \mathrm{mg} \mathrm{KOH} / \mathrm{g}, 1.94 \mathrm{meq} / \mathrm{kg}$ and 5.56 and were within the acceptable limit respectively. In FAME analysis, $4.5525 \%$ of omega- 3 fatty acids were present in the fish oil. The type of omega-3 fatty acids detected were eicosapentaenoic acid (EPA), heneicosapentaenoic acid (HPA), docosapentaenoic acid (DPA), and docosahexaenoic acid (DHA). Therefore, Atlantic salmon was proved to be a good source of omega-3 due to the present of omega3 fatty acids by using solvent (hexane:isopropanol) extraction method.

Supplementary Materials: The following are available online at www.mdpi.com/xxx/s1, Figure S1: title, Table S1: title, Video S1: title.

\section{Author Contributions:}

Iberahim NI: Conceptualization, investigation, funding acquisition and writing - original draft preparation

Tan BC: Methodology

Sohaimi KSA: Conceptualization, review and editing 
Funding: “This research was funded by Short Term Grant (9001-00509),Ministry of Higher Educational Malaysia.

Acknowledgments: The author would like to acknowledge the support from the Makmal Pencirian Struktur Molekul (MPSM), Centre for Research and Instrumentation Management (CRIM), Universiti Kebangsaan Malaysia (UKM) for instrument used and laboratory equipment provided by Universiti Malaysia Perlis.).

Conflicts of Interest: The authors declare no conflict of interest.

\section{References}

1. Haq M, Park SK, Kim MJ, Cho YJ and Chun BS 2018 J Food Drug Anal 26 545-556

2. Peinado I, Miles W, Koutsidis G 2016 Food Chem 212 612-619

3. Imanisa A, Santanumurti MB, Lamid M and Agustono 2019 IOP Conf Ser Earth Environ Sci 236012066

4. Arts MT, Brett MT and Kainz MJ Lipids in aquatic ecosystems. Epub ahead of print 2009 DOI: 10.1007/978-0387-89366-2

5. Adeniyi OD and Bawa AA 2006 Leonardo Journal of Sciences $833-42$

6. Jayasinghe P, Adeoti I and Hawboldt K 2013 JAOCS, J Am Oil Chem Soc 90 1903-1915

7. Zuta CP, Simpson BK, Chan HM and Phillips L 2003 Journal of the American Oil Chemists' Society $80933-936$

8. Vegneshwaran VR, Deepika D, Julia P, Sukhinder KC, Shella T, Heather M and Wade M 2014 J Food Process Technol 5. Epub ahead of print 2014.

9. $\quad$ Sarker MZI, Selamat J, Habib ASMA, Ferdosh S, Akanda MJH and Jaffri JM 2012 Int J Mol Sci 1311312 11322

10. Bako T, Umogbai VI and Garba AJ 2018 Journal of Postharvest Technology 06 69-82

11. Latip LD, Zzaman W and Yang TA 2014 Food Sci Technol 2 69-76

12. Lohani UC, Singh A, Thakur RR, Goutam S and Shahi NC 2018 Curr J Appl Sci Technol 25 1-12

13. Aryee ANA and Simpson BK 2009 J Food Eng 92 353-358

14. Tambunan JE, Suseno SH and Ibrahim B 2013 Global Journal of Biology, Agriculture E Health Sceinces 2 196202

15. Halim R, Gladman B, Danquah MK and Webley PA 2011 Bioresour Technol 102 178-185

16. Pavia DL, Lampman GM and Kriz GS Introduction to Spectroscopy. third.

17. Iberahim NI, Hamzah Z, Yin YJ and Sohaimi KSA 2018 MATEC Web of Conferences 18701005

18. Bako T, Umogbai VI and Awulu JO 2017 Agric Eng Int CIGR J 19 120-132

19. Uoonlue N and Muangrat R 2019 Journal of Food Process Engineering 42 1-16 